\title{
Alangium longiflorum Merr. Leaf Extract Induces Apoptosis in A549 Lung Cancer Cells with Minimal NFkB Transcriptional Activation
}

\author{
Cielo Mae D Marquez ${ }^{1}$, Jerremiah G Garcia ${ }^{1}$, Jessica G Antonio ${ }^{1}$, Sonia D \\ Jacinto $^{1,2}$, Michael C Velarde ${ }^{1,2 *}$
}

\begin{abstract}
The chemotherapy drug doxorubicin (DOX) is effective in treating many types of cancers. However, due to its pro-inflammatory and cardiotoxic side effects, other remedies have also been explored as alternative treatments. The plant Alangium longiflorum was reported to contain cytotoxic activity against cancer cells, but it is unclear whether this plant would also yield side effects similar to doxorubicin. Hence, this study investigated cytotoxic activity of A. longiflorum leaf extract against lung cancer cells and compared its pro-inflammatory and cardiotoxic side effects with those of DOX. Methods: Cytotoxic activity of A. longiflorum in human lung (A549) and breast (MCF-7) cancer cells was initially assessed by MTT assay and then was compared with doxorubicin. Presence of secondary metabolites in the leaf extract was examined by phytochemical screening. The ability of the plant extract to induce apoptosis was determined by measuring caspase-3/7 activity and apoptosis-related gene expression. Pro-inflammatory response was assessed by quantifying NFKB transcriptional activity and nuclear translocation with dual luciferase reporter and immunofluorescence assays, respectively. Cardiotoxicity was measured using zebrafish as a model organism. Results: A. longiflorum leaf extract displayed high cytotoxic activity against A549 versus MCF-7, which led this study to focus further on A549. Phytochemical screening showed that the extract contained terpenoids, alkaloids, phenols, cardiac glycosides, and tannins. The extract induced apoptosis through activation of caspase-3/7 and upregulation of pro-apoptotic genes without causing NFKB transcriptional activation and nuclear localization. The extract also did not significantly reduce heart function in zebrafish. Conclusion: Overall, our data suggested that extract from leaves of A. longiflorum can have the potential to serve as apoptotic agent towards lung cancer without inducing significant cardiotoxicity.
\end{abstract}

Keywords: Alangiaceae- cytotoxicity- cardiotoxicity- senescence- zebrafish

Asian Pac J Cancer Prev, 21 (8), 2453-2461

\section{Introduction}

Chemotherapy drugs, such as doxorubicin (DOX), induce cell death (apoptosis) or permanent growth arrest (cellular senescence) in cancer cells (Gonzalez et al., 2016). Although DOX is effective in preventing cancer progression, it damages normal tissues, including heart tissue, causing structural alterations, left ventricular dysfunction, and congestive heart failure (Cardinale et al., 2015; Maestrini et al., 2017). Hence, cardiotoxicity is a major concern during chemotherapy, as it may lead to morbidity and mortality of cancer patients (Khan et al., 2016). The dosage of DOX may often be reduced to avoid cardiotoxicity (Chang et al., 2017), but it can limit its efficacy. In addition to cardiotoxicity, DOX also induces cellular senescence and activates the inflammatory marker nuclear factor-kappa B $(\mathrm{NF} \kappa \mathrm{B})$, creating a pro-inflammatory environment which exacerbates DOX-induced cardiotoxicity (Fallah et al., 2019).

Alangium longiflorum (Family: Alangiaceae), commonly known as Malatapai, is found in Borneo and the Philippines (Sosef et al., 1998). It is listed as vulnerable on the IUCN Red List (World Conservation Monitoring Centre, 1998). This plant belongs to the genus Alangium, which contains several species used in traditional medicine. While only few studies were conducted on A. longiflorum, these studies reported remarkable cytotoxicity of the plant extracts toward cancer cells. For instance, A. longiflorum displayed notable cytotoxicity against U251 glioma cells by inhibiting transcriptional activity of hypoxia-induced factor (HIF1), which is activated during hypoxic conditions (Klausmeyer et al., 2008). The alkaloid demethylcephaeline from the stem bark of the plant also exhibited potent cytotoxicity against A549 lung and MCF-7 breast cancer cell lines 
(Sakurai et al., 2006).

While A. longiflorum extracts have strong cytotoxic activity against cancer cells, it remains unclear whether this natural product would elicit side effects similar to doxorubicin. Hence, this study aimed to determine cytotoxic activity of $A$. longiflorum leaf extract against lung cancer cells and compared its pro-inflammatory and cardiotoxic side effects with those of DOX.

\section{Materials and Methods}

\section{Plant Material}

A. longiflorum leaves ( $5 \mathrm{~kg}$ fresh weight) were collected from Mt. Makiling, Los Baños, Laguna on 17 April and 13 October 2017 after obtaining permission from Makiling Center for Mountain Ecosystems and being verified at the Jose Vera Santos Herbarium (Institute of Biology, UP Diliman, voucher specimen no. 21412). Leaves were washed, dried, homogenized, and soaked for $48 \mathrm{~h}$ in $100 \mathrm{mg} / \mathrm{ml}$ analytical grade absolute ethanol. Sample was filtered and solvent was removed using a rotary evaporator (Heidolph Hei-Vap) to yield the ethanolic extract (AL). AL was air-dried and oven-dried at $37^{\circ} \mathrm{C}$ prior to use.

\section{Phytochemical Screening}

AL was screened for the presence of secondary metabolites as described previously with slight modifications on alkaloid and terpenoid tests (Iqbal et al., 2015; Khanam et al., 2015). For alkaloids, AL was acidified with $1 \mathrm{ml} 1.5 \% \mathrm{HCl}$ before adding the Wagner's reagent. For flavonoids, $1 \mathrm{M} \mathrm{NaOH}$ was added dropwise to a $1 \mathrm{mg} / \mathrm{ml}$ of $\mathrm{AL}$ in distilled water, followed by addition of $1 \mathrm{M} \mathrm{HCl}$ to turn the solution colorless if flavonoids are present. Three trials were performed for each phytochemical test.

\section{Cell Culture Maintenance}

A549 and MCF-7 cells (American Type Culture Collection, Manassas, VA) were maintained in F12 HAMS Nutrient Mixture (Life Technologies 11765-054) and MEM (11095-080), respectively, supplemented with $10 \%$ FBS (10500-064) and $1 \mu \mathrm{g} / \mathrm{ml}$ gentamicin (Lonza CC-4081J). MCF-7 was also supplemented with 1\% insulin-transferrin-selenium A (Thermo Fisher Scientific). Cells were grown in a humidified $5 \% \mathrm{CO}_{2}$ incubator at $37^{\circ} \mathrm{C}$.

\section{$L C_{50}$ and $I C_{50}$ Determination}

Cells were seeded overnight at 8,000 to 12,000 cells/ well in 96-well plates and exposed to $\operatorname{AL}(0.02 \mu \mathrm{g} / \mathrm{ml}$ to $200 \mu \mathrm{g} / \mathrm{ml})$, DOX $(0.000001-10 \mu \mathrm{g} / \mathrm{ml})$, and vehicle for $24 \mathrm{~h}$ or $72 \mathrm{~h}$ with at least three trials. After incubation, $\mathrm{LC}_{50}$ and $\mathrm{IC}_{50}$ were evaluated by MTT assay as described previously (Dante et al., 2019). Absorbance was read at $570 \mathrm{~nm}$ using Varioskan Flash multimode reader (Thermo Fisher Scientific).

\section{Real Time Cell Proliferation Assay}

Cells were seeded overnight at 1,000 cells/well in a 96-well white plate and were treated with vehicle control or $\mathrm{LC}_{50}$ values of AL $(6.5 \mu \mathrm{g} / \mathrm{ml})$ and DOX $(5 \mu \mathrm{g} /$ $\mathrm{ml}$ ) for $24 \mathrm{~h}$ done in quadruplicates. Cell proliferation was monitored every $24 \mathrm{~h}$ for 3 days at $37^{\circ} \mathrm{C}$ with RealTimeGlo $^{\mathrm{TM}}$ MT Cell Viability Assay (Promega) using a Varioskan Flash reader.

\section{Dual Luciferase Assay}

Cells were seeded overnight in a 6-well plate and transduced with lentiviral $\mathrm{NF} \kappa \mathrm{B}$ (puro) and CMV-Renilla control (hygro) (Qiagen) reporters at $1 \mathrm{TU} /$ cell in antibiotic-free medium for $24 \mathrm{~h}$, followed by incubation in $3 \mathrm{ml}$ culture medium containing $1 \mu \mathrm{g} /$ $\mathrm{ml}$ puromycin and $750 \mu \mathrm{g} / \mathrm{ml}$ hygromycin for another $72 \mathrm{~h}$. Cells were plated overnight at 8,000 cells/well in 96-well plates and treated with AL and DOX for $72 \mathrm{~h}$. Luciferase activities from cell lysates were measured as relative luminescence units (RLU) by Dual-luciferase ${ }^{\circledR}$ assay (Promega) using Varioskan Flash. RLU for firefly luciferase was normalized to RLU of Renilla luciferase. Relative NFKB transcriptional activity was calculated by dividing the normalized RLU for treatment group with their respective vehicle controls.

\section{Immunofluorescence}

Cells were seeded overnight at 500 to 2,000 cells/well in 96-well plates and exposed to vehicle and $\mathrm{LC}_{50}$ of $\mathrm{AL}$ and DOX for $24 \mathrm{~h}$, followed by incubation in fresh medium for another $48 \mathrm{~h}$. Cells were fixed in $3.7 \%$ formaldehyde for 15 minutes, permeabilized with $0.1 \%$ Triton X-100 for 10 minutes, and blocked with $1 \%$ BSA for 30 minutes at room temperature, with PBS washing in between incubations. Cells were incubated consecutively with NFкB (p65, RelA) antibody (EMD Millipore PC138) (1:500 in 1\% BSA) overnight at $4^{\circ} \mathrm{C}$, CFTM $488 \mathrm{~A}$ secondary antibody (Sigma-Aldrich SAB4600234) (1:1,000 in 1\% BSA) for $1 \mathrm{~h}$ in the dark at room temperature, and $8.12 \mu \mathrm{M}$ Hoechst 33342 (Thermo Fisher Scientific H3570) for 15 minutes at room temperature, with PBS washing in between incubations. Photomicrographs $(\mathrm{n}=15)$ were taken at 200x magnification using an inverted fluorescence microscope (Carl Zeiss ${ }^{\mathrm{TM}}$ Axio Vert A.1 with Axiocam IC).

\section{Apoptosis Assay}

Cells were treated with $\mathrm{LC}_{50}$ of AL or DOX, mitomycin $\mathrm{C}(\mathrm{MMC}, 300 \mu \mathrm{M})$ and vehicle for $24 \mathrm{~h}$ and fixed with $3.7 \%$ formaldehyde for 15 minutes at room temperature. Cells were incubated with $7.5 \mu \mathrm{M}$ CellEvent ${ }^{\mathrm{TM}}$ Caspase- $3 / 7$ substrate reagent for $1 \mathrm{~h}$ at $37^{\circ} \mathrm{C}$ and counterstained with $8.12 \mu \mathrm{M}$ Hoechst 33342 for 15 minutes at room temperature following the manufacturer's protocol (Invitrogen). Photomicrographs ( $\mathrm{n}=10)$ were taken at $400 \mathrm{x}$ magnification to quantify the percent number of apoptotic cells per treatment.

\section{RNA Isolation and cDNA Synthesis}

Cells were grown overnight in 6-well plate and treated with AL, DOX, or vehicle for 24h. Total RNA was extracted using TRIzol ${ }^{\mathrm{TM}}$ (Invitrogen), quantified by NanoDrop 2000, and assessed for RNA quality under $2 \%$ agarose gel electrophoresis. cDNA synthesis was performed using High Capacity cDNA Reverse Transcription Kit (Applied Biosystems), consisting of 
$2 \mu \mathrm{g}$ RNA, 1X RT buffer, 4mM dNTP mix, $1 \mathrm{X}$ random primers, and $50 \mathrm{U}$ Multiscribe ${ }^{\mathrm{TM}}$ Reverse Transcriptase in a $20 \mu \mathrm{l}$ reaction mix, as follows: $25^{\circ} \mathrm{C}$ for 10 minutes, $37^{\circ} \mathrm{C}$ for 120 minutes, and $85^{\circ} \mathrm{C}$ for 85 minutes. The resulting amplicons were diluted to a final volume of $100 \mu \mathrm{l}$ nuclease-free water and stored at $20^{\circ} \mathrm{C}$.

\section{Gene Expression Analysis}

qPCR mastermix contained 1X SYBR Green (Thermo Fisher Scientific), $0.1 \mu \mathrm{M}$ forward and reverse primers (Table 1), and 40ng of cDNA in RNAse/DNAse-free water, as follows: $95^{\circ} \mathrm{C}$ for 10 minutes, 40 cycles of $\left[95^{\circ} \mathrm{C}\right.$ for $15 \mathrm{sec}, 60^{\circ} \mathrm{C}$ for $30 \mathrm{sec}, 72^{\circ} \mathrm{C}$ for $30 \mathrm{sec}$, and melt curve stage of $95^{\circ} \mathrm{C}$ for $15 \mathrm{sec}, 60^{\circ} \mathrm{C}$ for 1 minute, and $95^{\circ} \mathrm{C}$ for $15 \mathrm{sec}$ in a StepOne Plus qPCR machine. Relative mRNA expression was calculated using the comparative cycle threshold (CT) values method with beta-actin (ACTB) as housekeeping gene. Three independent trials were performed.

\section{Zebrafish Cardiotoxicity and Mortality Assays}

Zebrafish experiments were performed at the Institute of Biology, University of the Philippines Diliman, following a protocol approved by the Institutional Animal Care and Use Committee. Danio rerio (zebrafish) were obtained from the Freshwater Aquaculture Center, Central Luzon State University, Science City of Muñoz. Spawning was induced by exposing adult fish to light for
Alangium longiflorum Merr. Leaf Extract Induces Apoptosis

$1 \mathrm{~h}$, following a $12 \mathrm{~h}$ light-dark cycle. Blastula eggs were incubated for three days at $28^{\circ} \mathrm{C}$ in a petri dish containing embryo medium $\left(2.65 \mathrm{mM} \mathrm{CaCl}_{2}, 1 \mathrm{mM} \mathrm{MgSO}, 0.8 \mathrm{mM}\right.$ $\mathrm{NaHCO}_{3}$, and $0.08 \mathrm{mM} \mathrm{KCl}$ ), then treated with $\mathrm{AL}$, DOX, or vehicle for $48 \mathrm{~h}$ in a 24 -well plate at five zebrafish per well in triplicates $(n=15)$. Heart function was assessed by counting heart beats per minute. Percent cumulative mortality was calculated as number of dead fish after two days following treatment, divided by the total number of fish per treatment multiplied by 100 .

\section{Statistical analysis}

All data were expressed as means \pm SEM. Student's t-test, one-way, and two-way ANOVA test with post-hoc analysis (Tukey) were done by GraphPad Prism 7. Differences with P-values $<0.05$ were considered significant.

\section{Results}

\section{AL induced cytotoxicity}

Lung and breast cancers are the leading types of cancer worldwide (Aggarwal et al., 2016). Hence, this study tested whether AL is effective against A549 lung and MCF-7 breast cancer cells. AL was more cytotoxic against A549 than MCF-7 cells $(\mathrm{p}=0.0048)$, with an $\mathrm{LC}_{50}$ of $6.34 \mu \mathrm{g} / \mathrm{ml}$ versus $39.61 \mu \mathrm{g} / \mathrm{ml}$, respectively, when treated for $24 \mathrm{~h}$ (Figure 1A, Table 2). On the other hand,
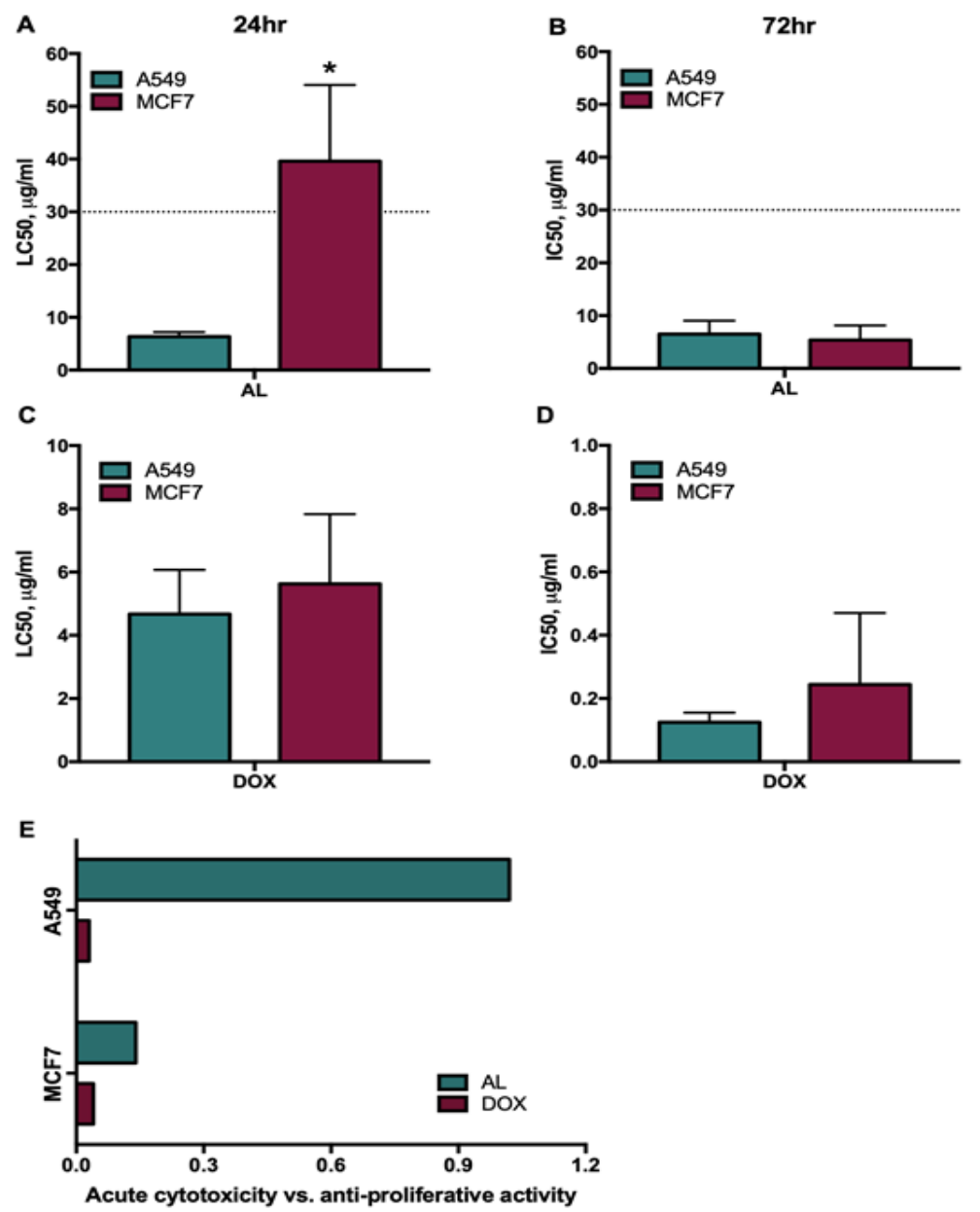

Figure 1. Differential Cytotoxicity and Inhibition of Proliferation in A549 and MCF-7 Cell Lines 

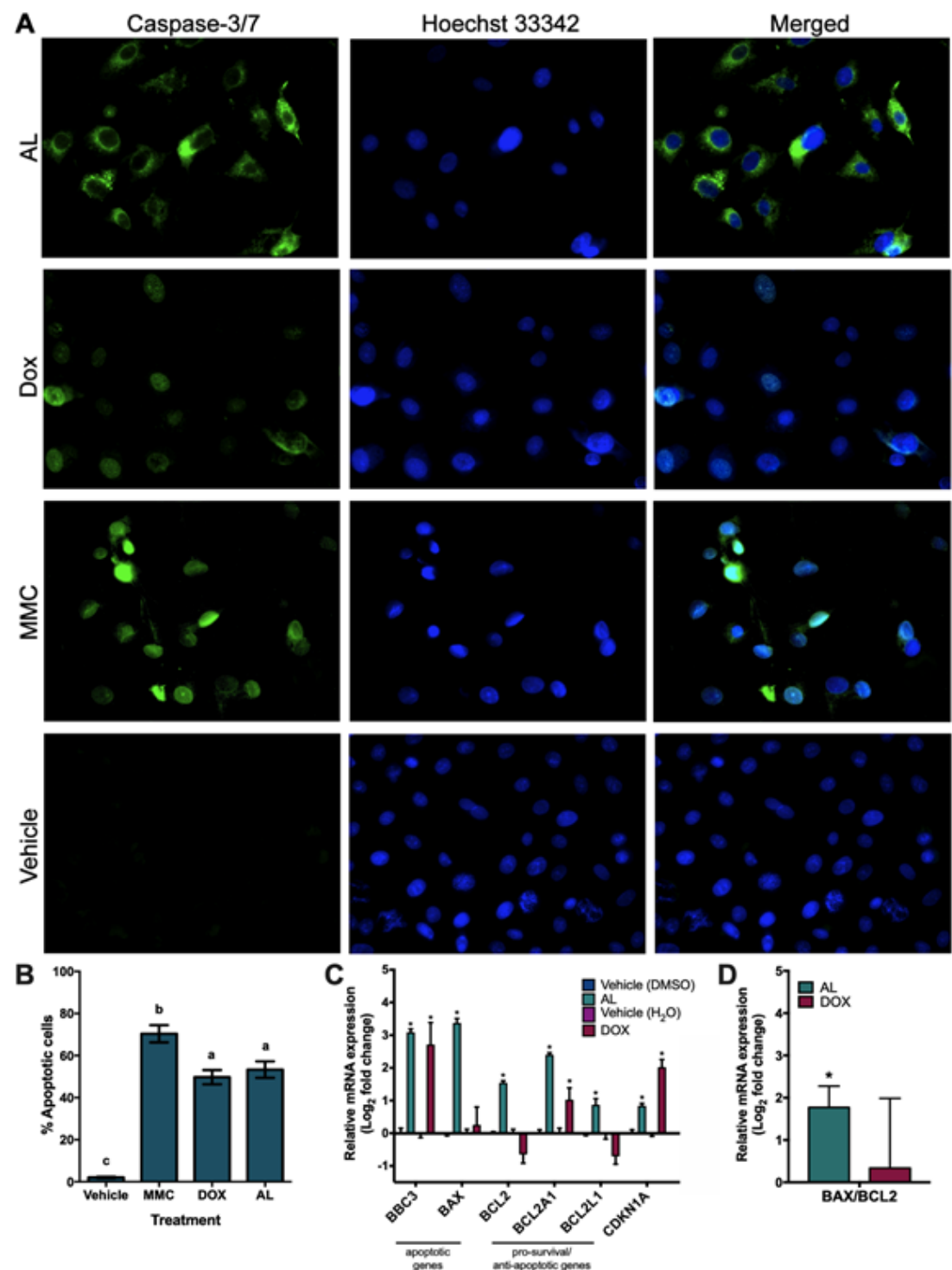

Figure 2. Increased Apoptosis in A549 Cells Treated with AL. (A) Representative fluorescence micrographs of cells. (B) Percent total apoptotic cells. (C) Relative mRNA expression of genes. (D) mRNA expression ratio of BAX/BCL2. Different letters and asterisks indicate significant differences at $\mathrm{p}<0.05$.

AL inhibited proliferation in A549 and MCF-7 with a similar $\mathrm{IC}_{50}$ of $6.48 \mu \mathrm{g} / \mathrm{ml}$ and $5.39 \mu \mathrm{g} / \mathrm{ml}$, respectively, when exposed for $72 \mathrm{~h}(\mathrm{p}=0.6558)$ (Figure 1B, Table 2). Given that the American National Cancer Institute (NCI) has established that crude extracts with $\mathrm{LC}_{50}$ or $\mathrm{IC}_{50}$ values of $\leq 30 \mu \mathrm{g} / \mathrm{ml}$ are considered cytotoxic and/or anti-proliferative (Abdul-Hafeez et al., 2020), AL may have promising anticancer potential.
To compare the activity of $\mathrm{AL}$ with $\mathrm{DOX}$, the $\mathrm{LC}_{50}$ and $\mathrm{IC}_{50}$ values of DOX against A549 and MCF-7 were also determined. DOX displayed cytotoxic activity towards A549 and MCF-7 at an $\mathrm{LC}_{50}$ of $4.67 \mu \mathrm{g} / \mathrm{ml}$ and $5.62 \mu \mathrm{g} / \mathrm{ml}$, respectively, (Figure 1C, Table 2), suggesting that the drug had a similar efficacy with AL in inducing cytotoxicity within $24 \mathrm{~h}(\mathrm{p}=0.3336)$. However, longer treatment of DOX inhibited proliferation in A549 and

Table 1. Primer Sequence Used for qPCR

\begin{tabular}{lll}
\hline Gene Name & Forward Primer (5'to 3') & Reverse Primer (5'to 3') \\
\hline$B B C 3$ & TTGTGCTGGTGCCCGTTCCA & AGGCTAGTGGTCACGTTTGGCT \\
$B A X$ & TGATGGACGGGTCCGGG & CACAGGGCCTTGAGCACC \\
$B C L 2$ & GGATAACGGAGGCTGGGATG & GACTTCACTTGTGGCCCAG \\
$B C L 2 A 1$ & CAGCAAATTGCCCCGGATG & CCATTTTCCTCTTCTTGTGGG \\
$B C L 2 L 1$ & GAGCTGGTGGTTGACTTTCTC & TCCATCTCCGATTCAGTCCCT \\
$C D K N 1 A$ & GTTTTCAGGCGCCATGTCAG & CATTAGCGCATCACAGTCGC \\
$I L 6$ & CACAAGCGCCTTCGGTCCAG & CATGTCTCCTTTCTCAGGGC \\
$A C T B$ & ACCATGTACCCTGGCATTG & AGGAAAGACACCCACCTTGA \\
\hline
\end{tabular}



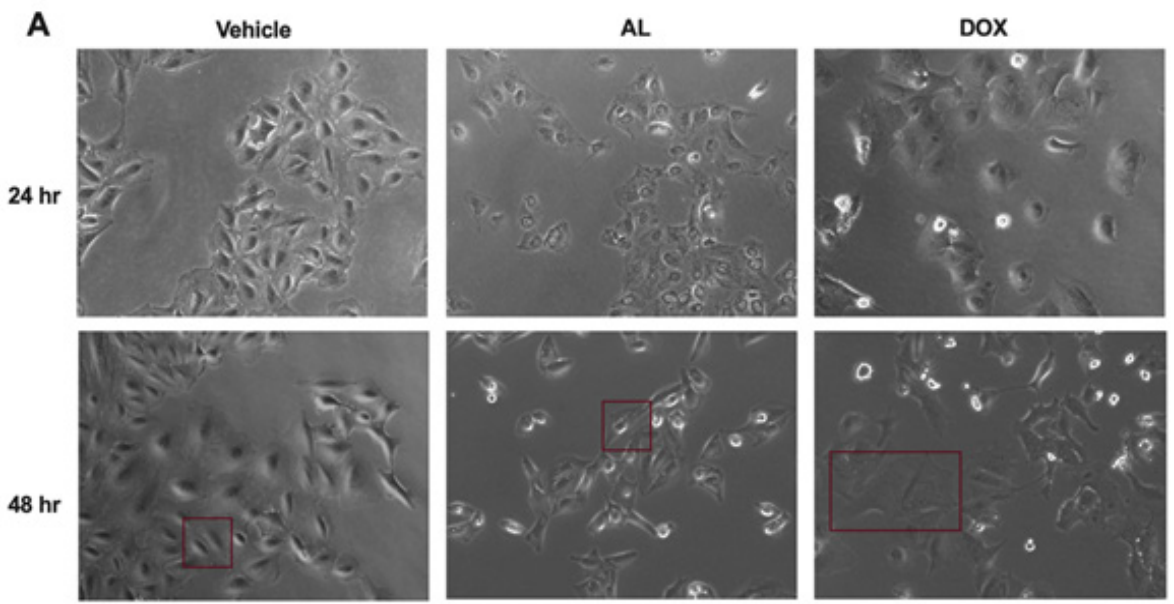

B

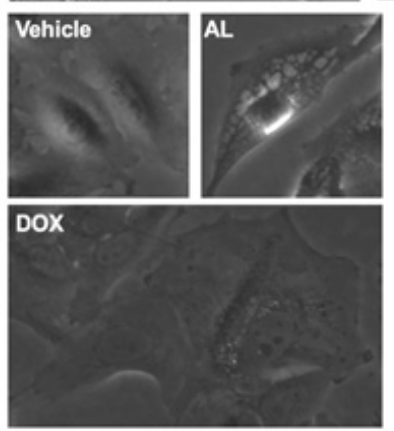

C

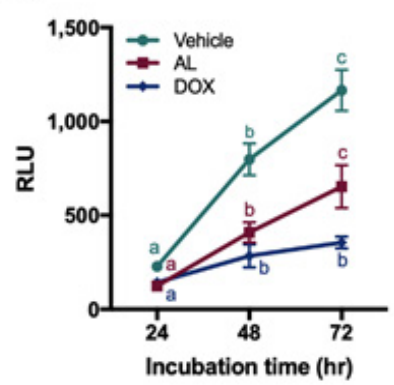

D

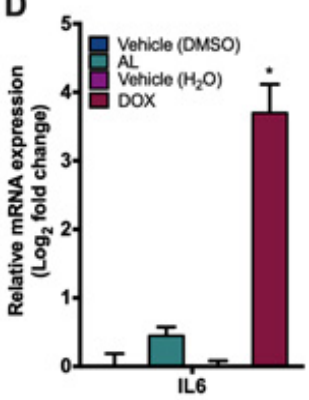

Figure 3. Senescence-Like Phenotype in A549 Cells Treated with DOX but not AL. (A) Photomicrographs of cells at $24 \mathrm{~h}$ and $48 \mathrm{~h}$. (B) Insets of photomicrographs in A. (C) Inhibition of cell proliferation (RLU \pm SEM). (D) Relative mRNA expression of IL6. Different letters and asterisks indicate significant differences at $p<0.05$.

MCF-7 at a very low $\mathrm{IC}_{50}$ of $125 \mathrm{ng} / \mathrm{ml}$ and $32.50 \mathrm{ng} / \mathrm{ml}(\mathrm{p}$ $=0.3661$ ), respectively (Figure 1D, Table 2 ). This suggests that DOX is more potent than AL in inhibiting cancer cell proliferation than inducing cell death. Indeed, AL-treated cells displayed higher acute cytotoxicity versus anti-proliferative index than DOX (Figure 1E), suggesting that the extract induces more A549 cells to undergo cell death than growth arrest. Since A549 was more sensitive to the cytotoxic effect of AL than MCF-7, succeeding bioassays involving AL were focused on A549. Moreover, given that $\mathrm{AL}$ induced cytotoxicity in A549 within 24h, $\mathrm{LC}_{50}$ at this exposure time was the treatment condition used in succeeding experiments.

To further assess the classes of secondary metabolites present in the extract, we performed a phytochemical screen. AL extracts contained alkaloids, terpenoids, cardiac glycosides, phenols, and tannins (Table 3), suggesting that these classes of compounds may be involved in cytotoxicity of the plant extract.

\section{AL induced apoptosis}

Since apoptosis remains to be the preferred mode of action for cancer therapies (Baig et al., 2016), this study further determined whether AL induces apoptosis in A549.

$\mathrm{AL}$ at its $\mathrm{LC}_{50}$ increased activation of the apoptosis effector caspase- $3 / 7$ in $53.33 \%$ of A549 cells within $24 \mathrm{~h}(\mathrm{p}<0.0001)$ (Figure 2A-B). Likewise, DOX at its $\mathrm{LC}_{50}$ caused $49.73 \%$ of A459 cells to undergo apoptosis within 24h $(\mathrm{p}<0.0001)$ (Figure 2B). Both treatments were compared with an apoptotic inducer mitomycin $\mathrm{C}$ and DMSO to serve as positive and negative controls, respectively.

Apoptosis is associated with increased expression of the pro-apoptosis gene BBC3 (also called PUMA) (Sonntag et al., 2014) and increased expression ratios of the pro-apoptosis gene BAX over the pro-survival BCL2 gene family (Xu et al., 2016), while inhibition of cell proliferation is associated with increased gene expression of the cell cycle inhibitor cyclin-dependent kinase inhibitor 1A CDKN1A (Karimian et al., 2016). AL significantly increased BBC3 mRNA expression $(p<0.0001)$ and

Table 2. Comparison of $\mathrm{LC}_{50}$ and $\mathrm{IC}_{50}$ Values of $\mathrm{AL}$ and DOX

\begin{tabular}{lcccc}
\hline Treatment & Cancer Cell lines & $\mathrm{LC}_{50}$ & $\mathrm{IC}_{50}$ & Acute toxicity vs. anti-proliferative activity \\
\hline AL & A549 & $6.34 \pm 0.88 \mu \mathrm{g} / \mathrm{ml}$ & $6.48 \pm 2.57 \mu \mathrm{g} / \mathrm{ml}$ & 1.02 \\
& $\mathrm{MCF}-7$ & $39.61 \pm 14.45 \mu \mathrm{g} / \mathrm{ml}$ & $5.39 \pm 2.74 \mu \mathrm{g} / \mathrm{ml}$ & 0.14 \\
DOX & $\mathrm{A} 549$ & $4.67 \pm 1.40 \mu \mathrm{g} / \mathrm{ml}$ & $0.125 \pm 0.03 \mu \mathrm{g} / \mathrm{ml}$ & 0.03 \\
& $\mathrm{MCF}-7$ & $5.62 \pm 2.21 \mu \mathrm{g} / \mathrm{ml}$ & $0.244 \pm 0.226 \mu \mathrm{g} / \mathrm{ml}$ & 0.04 \\
\hline
\end{tabular}

$\mathrm{LC}_{50}$ and $\mathrm{IC}_{50}$ values for each treatment were shown as means \pm SEM. At least three independent trials were performed for each experiment. Ratio of acute toxicity vs. anti-proliferative activity for $\mathrm{AL}$ and DOX were included for comparison. 

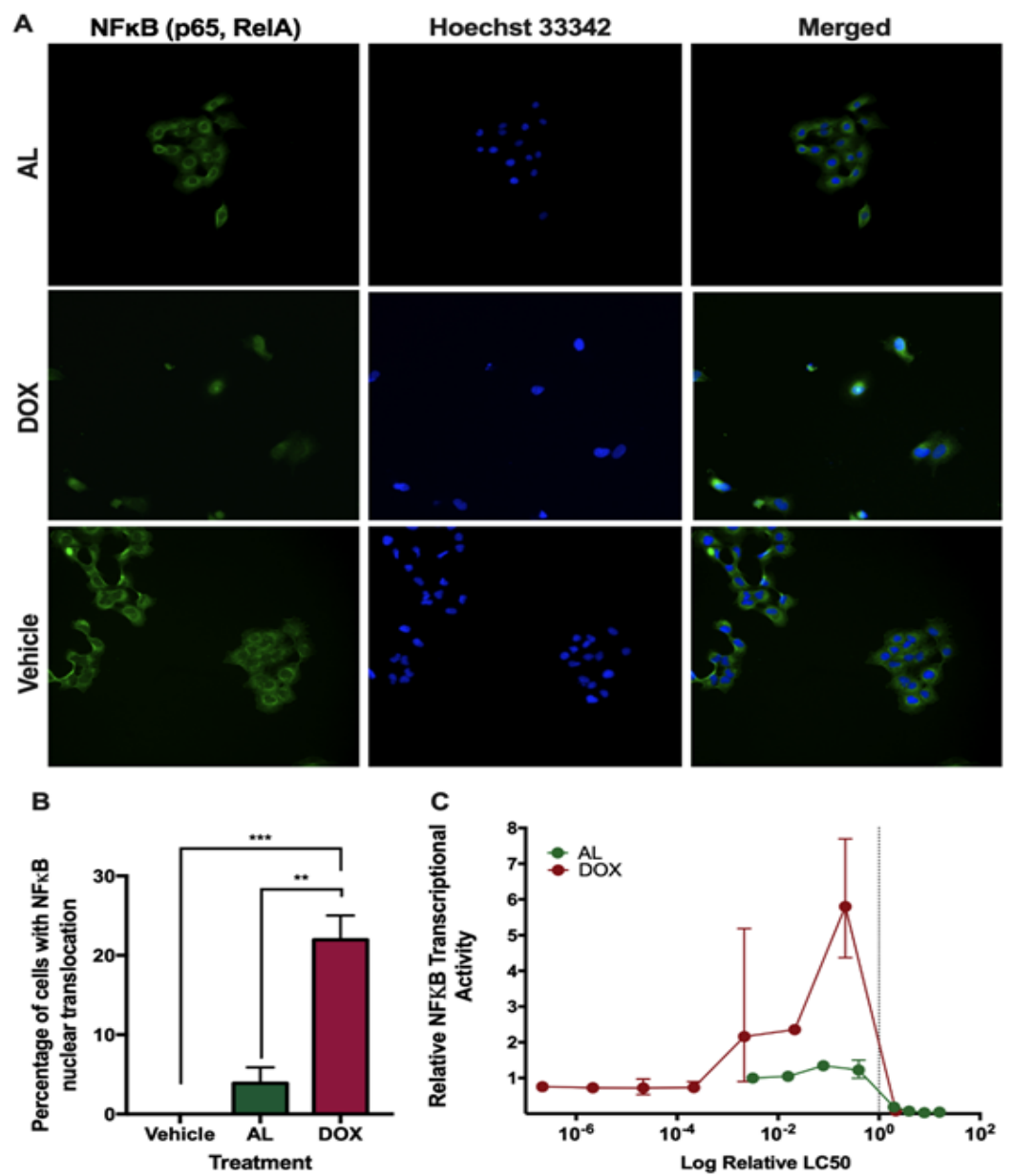

Figure 4. Minimal NFkB Nuclear Translocation and Transcriptional Activity in A549 Treated with AL. (A)

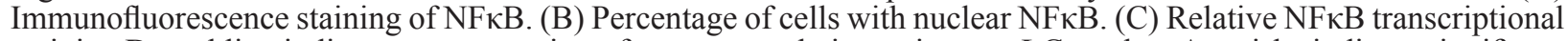
activity. Dotted line indicates concentration of treatment relative to its own $\mathrm{LC}_{50}$ value. Asterisks indicate significant differences $(* * \mathrm{p}<0.01)$ and $(* * * \mathrm{p}<0.001)$.

BAX/BCL2 expression ratios ( $p=0.0001)$ (Figure 2C-D), consistent with its ability to induce apoptosis. In contrast, while DOX significantly increased expression of $\mathrm{BBC} 3$ $(p=0.0035)$ (Figure 2C), it did not significantly increase BAX/BCL2 ratios $(p=0.6302)$ (Figure $2 D)$. Both AL $(p=0.0002)$ and DOX $(p<0.0001)$ increased expression of CDKN1A, suggesting that AL and DOX can inhibit proliferation.

DOX versus AL for inducing a senescence-like phenotype DOX inhibits cancer growth through induction of

Table 3. Phytochemical Screening of Secondary Metabolites in AL

\begin{tabular}{lc}
\hline Secondary Metabolites & AL \\
\hline Saponins & - \\
Terpenoids & + \\
Flavonoids & - \\
Alkaloids (Wagner's Test) & + \\
Cardiac glycosides & + \\
Phenols & + \\
Tannins & + \\
\hline
\end{tabular}

$\overline{\text { Three independent trials were performed for each secondary metabolite }}$ tested apoptosis and senescence depending on dose, cell type, and culture conditions (Marino Gammazza et al., 2017; Srdic-Rajic et al., 2017). Indeed, cells treated with DOX showed an enlarged cell phenotype in this study (Figure 3A-B), reminiscent of senescent cells (Neurohr et al., 2019). These cells no longer divided even if DOX was removed from the media $(\mathrm{p}=0.0884)$ (Figure $3 \mathrm{C})$, further confirming that the remaining cells underwent a permanent cell cycle arrest. In contrast, cells treated with AL remained relatively small in size and had several distinctly large vesicles (Figure 3A-B). These remaining cells continued to divide when $\mathrm{AL}$ was removed from the media after treatment $(p=0.0027)$ (Figure 3C). Hence, while AL and DOX both induced apoptosis (Figure 2A-B), DOX but not $\mathrm{AL}$, induced cellular senescence in A549 cells.

Cellular senescence is a strong tumor suppressor mechanism to limit proliferation of cancer cells. However, senescent cells can also increase expression of pro-inflammatory cytokines, such as IL6 (Coppé et al., 2010; Wiley et al., 2018). Hence, we focused on testing whether AL can also target the same gene. DOX, but not AL, significantly increased IL6 gene expression $(p<0.0001)$ (Figure 3D), suggesting that AL does not lead to expression of the pro-inflammatory cytokine IL6 $(p=0.0761)$. Overall, these results suggest that AL can be 
A

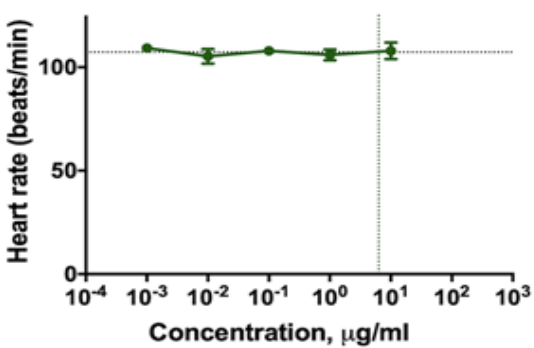

C

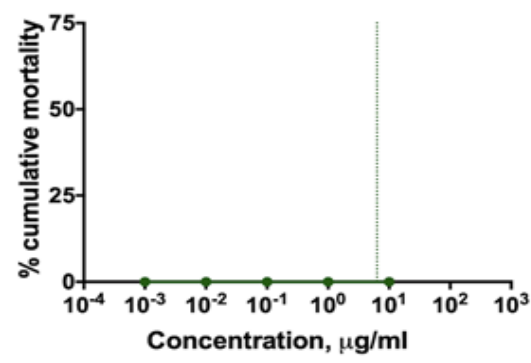

B

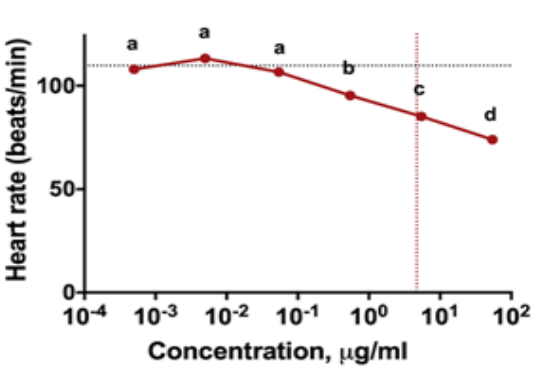

D

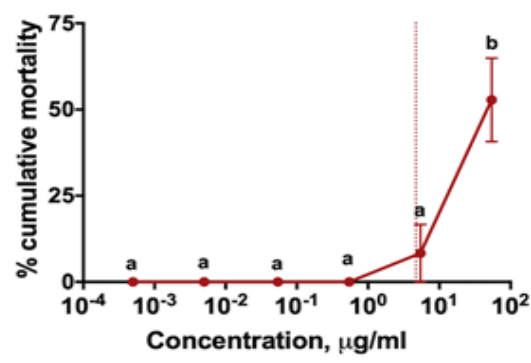

Figure 5. Reduced Heart Function in Zebrafish Treated with DOX. (A,B) Heart rate and (C,D) percent mortality of zebrafish for both treatments compared to vehicle control (horizontal lines). Letters indicate significant differences at $\mathrm{p}<0.05$. Vertical lines represent $\mathrm{LC}_{50}$ of $\mathrm{AL}$ and $\mathrm{DOX}$.

a strong inducer of apoptosis with minimal IL6 expression, while DOX is an inducer of apoptosis and senescence with IL6 upregulation.

\section{AL showing minimal $N F \kappa B$ transcriptional activation}

$\mathrm{NF} \kappa \mathrm{B}$ upregulates expression of pro-inflammatory cytokines, including IL6 (Nan et al., 2018). Hence, this study explored the ability of DOX and AL to activate

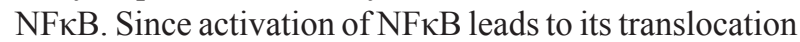
from the cytoplasm into the nucleus, we checked for subcellular distribution of $\mathrm{NF} \kappa \mathrm{B}$ by immunofluorescence after treatment with $\mathrm{AL}$ and DOX. AL induced NFкB translocation to the nucleus $(p=0.0022)$, but this was significantly lower than that induced by DOX $(\mathrm{p}=0.0008)$ (Figure 4A-B).

We further checked for NFאB transcriptional activity using a luciferase reporter assay driven by a promoter containing NFkB response elements. A549 cells treated with AL had lower NFKB transcriptional activity than cells treated with DOX, which yielded the highest activity at a concentration below its $\mathrm{LC}_{50}$ value (Figure $4 \mathrm{C}$ ). Given that $\mathrm{NF} \kappa \mathrm{B}$ activation is associated with inflammation, the reduced ability of AL versus DOX to induce NFאB nuclear translocation and transcriptional activation suggests that the extract may elicit lower inflammatory side effects than the chemotherapeutic drug.

\section{AL and cardiotoxicity}

Heart failure is a serious side effect following DOX treatment (Cardinale et al., 2015; Maestrini et al., 2017), so this study explored the effects of AL on heart function in zebrafish. Heart rate (beats/minute) of zebrafish larvae was used as a parameter for cardiotoxicity. AL extract up to $10 \mu \mathrm{g} / \mathrm{ml}$ did not reduce heart rate in zebrafish $(\mathrm{p}=0.8467)$ (Figure 5A). This concentration was above the $\mathrm{LC}_{50}$ value of the extract against A549, suggesting that AL induces minimal cardiotoxicity on zebrafish. In contrast, DOX significantly lowered heart rate in zebrafish starting at a concentration of $0.54 \mu \mathrm{g} / \mathrm{ml}(\mathrm{p}=0.0002)$ (Figure 5B). This concentration was several folds below the $\mathrm{LC}_{50}$ of the drug, confirming the cardiotoxicity of DOX. AL extract also did not cause death in zebrafish larvae across all treatment concentrations (Figure 5C), while DOX induced mortality in some of the fish larvae at $\geq \mathrm{LC}_{50}$ concentrations ( $\mathrm{p}=$ 0.0002) (Figure 5D). The high survival rate of zebrafish within the given range of concentrations suggests minimal overall toxic effect of AL in zebrafish larvae.

\section{Discussion}

DOX causes topoisomerase-II inhibition, impaired DNA replication, and DNA double strand breaks (Mitry and Edwards, 2016), which can all lead to cellular senescence (Marino Gammazza et al., 2017; Fallah et al., 2019). Indeed, chronic treatment of DOX at low doses can permanently arrest proliferation in MCF-7 cancer cell lines and other cells isolated from different types of solid tumors (Chang et al., 1999; Srdic-Rajic et al., 2017). DOX induces a senescence-like phenotype in cancer cells, resulting in G2/M arrest, increased cell size, and senescence-associated beta-galactosidase activity (Marino Gammazza et al., 2017; Srdic-Rajic et al., 2017). In this study, we showed that AL was more cytotoxic and less likely to induce cellular senescence, as supported by its high efficacy to induce acute cytotoxic versus antiproliferative activity and inability to increase number of cells with enlarged cell phenotype and gene expression of IL6.

The ability of DOX to induce senescence may promote inflammation and exacerbate heart dysfunction (Mitry and Edwards, 2016). Indeed, previous studies demonstrated that DOX induced cardiomyopathy and inflammation 
(Fallah et al., 2019). Consistent with this, we also showed that DOX at several folds below its $\mathrm{LC}_{50}$ was sufficient to reduce heart function in zebrafish, as observed in previous findings (Han et al., 2015). This is in stark contrast to AL which did not induce senescence and did not decrease heart function in zebrafish even at concentrations within its $\mathrm{LC}_{50}$. While only one parameter was used to assess possible cardiotoxic effect of AL, this study showed that the effective concentration of AL that caused cytotoxicity on cancer cells may only have minimal cardiotoxic side effects in zebrafish.

This study showed that AL was cytotoxic to A549 cells but were more anti-proliferative against MCF-7 cells. The molecular mechanism behind this is still unclear, but it is thought that differences in sensitivity and responsiveness of cancer cells may result from the heterogeneity among cancer cell types and tissue specificity of components of the extract (Tiwary et al., 2015; Baram et al., 2019). MCF-7 contains estrogen receptors which increases cell proliferation and pro-survival signaling upon ligand activation (Jameera Begam et al., 2017). It is interesting to speculate that the presence of phenolic compounds in $\mathrm{AL}$ may cause strong growth inhibition in MCF-7, as phenolic compounds can antagonize estrogen receptors (Scott et al., 2016; Pang et al., 2018). Further studies need to be done to investigate the contribution of different components of the extract and to elucidate the mechanism of action between MCF-7 and A549.

The cytotoxicity of AL in cancer cells was also demonstrated by other studies. For example, the alkaloid 8-hydroxytubulosine from AL leaves displayed broadspectrum inhibition in a panel of cancer cell lines (Takeuchi et al., 2018). The alkaloid demethylcephaeline from the stem bark of the plant exhibited potent cytotoxicity against A549 and MCF-7 (Sakurai et al., 2006). Tubulosine from the root extract of the same plant also displayed remarkable cytotoxicity against U251 glioma cells by inhibiting transcriptional activity of hypoxia-induced HIF1 (Klausmeyer et al., 2008). While these studies focused on the efficacy of pure alkaloids, it is also worth to consider the possible advantages of using a mixture (i.e. crude extract) over pure isolates. Although numerous single active constituents have been successfully derived from natural products, positive interactions and multifactorial effects between or among the components present in the crude extract sometimes make the extract more effective than a single compound (Ouhtit et al., 2013; Liu et al., 2016; Kapinova et al., 2017).

In conclusion, this study showed that AL can be a promising candidate natural product against lung cancer cells by inducing apoptotic signals with minimal expression of pro-inflammatory cytokine. Due to the low cardiotoxicity of AL in zebrafish, further studies should be done to test its potency in eliminating lung cancer in vivo.

\section{Acknowledgements}

This article was funded by the University of the Philippines Diliman, Natural Sciences Research Institute (BIO-17-1-05) [Velarde \& Jacinto], University of the Philippines Diliman, Office of the Vice President for
Academic Affairs (OVPAA-BPhD-2016-08) [Velarde], and the Department of Science and Technology, Philippine Council for Health Research and Development (FP 160028) [Velarde]. We would like to thank Dr. Emmanuel M. Vera Cruz and Ms. Julieta D. Holasca for providing the zebrafish in this study.

\section{References}

Abdul-Hafeez EY, Orabi MAA, Ibrahim OHM, Ilinskaya O, Karamova NS (2020). In vitro cytotoxic activity of certain succulent plants against human colon, breast and liver cancer cell lines. South African J Bot, 131, 295-301.

Aggarwal A, Lewison G, Idir S, et al (2016). The state of lung cancer research: A global analysis. J Thorac Oncol, 11, 1040-50.

Baig S, Seevasant I, Mohamad J, et al (2016). Potential of apoptotic pathway-targeted cancer therapeutic research: Where do we stand? Cell Death Dis, 7, e2058.

Baram L, Peled E, Berman P, et al (2019). The heterogeneity and complexity of Cannabis extracts as antitumor agents. Oncotarget, 10, 4091-106.

Cardinale D, Colombo A, Bacchiani G, et al (2015). Early detection of anthracycline cardiotoxicity and improvement with heart failure therapy. Circulation, 131, 1981-8.

Chang B-D, Broude EV, Dokmanovic M, et al (1999). A senescence-like phenotype distinguishes tumor cells that undergo terminal proliferation arrest after exposure to anticancer agents. Cancer Res, 59, 3761-7.

Chang H-M, Moudgil R, Scarabelli T, Okwuosa TM, Yeh ETH (2017). Cardiovascular complications of cancer therapy. J Am Coll Cardiol, 70, 2536-51.

Coppé J-P, Patil CK, Rodier F, et al (2010). A human-like senescence-associated secretory phenotype is conserved in mouse cells dependent on physiological oxygen. PLoS One, 5, e9188.

Dante RAS, Ferrer RJE, Jacinto SD (2019). Leaf extracts from dillenia philippinensis rolfe exhibit cytotoxic activity to both drug-sensitive and multidrug-resistant cancer cells. Asian Pacific J Cancer Prev, 20, 3285-90.

Fallah M, Mohammadi H, Shaki F, et al (2019). Doxorubicin and liposomal doxorubicin induce senescence by enhancing nuclear factor kappa B and mitochondrial membrane potential. Life Sci, 232, 116677.

Gonzalez LC, Ghadaouia S, Martinez A, Rodier F (2016). Premature aging/senescence in cancer cells facing therapy: good or bad?. Biogerontology, 17, 71-87.

Han Y, Zhang J, Qian J, Hu C (2015). Cardiotoxicity evaluation of anthracyclines in zebrafish (Danio rerio). J Appl Toxicol, 35, 241-52.

Iqbal E, Salim KA, Lim LBL (2015). Phytochemical screening, total phenolics and antioxidant activities of bark and leaf extracts of Goniothalamus velutinus (Airy Shaw) from Brunei Darussalam. J King Saud Univ Sci, 27, 224-32.

Jameera Begam A, Jubie S, Nanjan MJ (2017). Estrogen receptor agonists/antagonists in breast cancer therapy: A critical review. Bioorg Chem, 71, 257-74.

Kapinova A, Stefanicka P, Kubatka P, et al (2017). Are plantbased functional foods better choice against cancer than single phytochemicals? A critical review of current breast cancer research. Biomed Pharmacother, 96, 1465-77.

Karimian A, Ahmadi Y, Yousefi B (2016). Multiple functions of p21 in cell cycle, apoptosis and transcriptional regulation after DNA damage. DNA Repair (Amst), 42, 63-71.

Khan A, Singh R, Rahim A, et al (2016). Incidence, time of occurrence and response to heart failure therapy in patients 
with anthracycline cardiotoxicity. Hear Lung Circ, 25, 115.

Khanam Z, Wen CS, Bhat IUH (2015). Phytochemical screening and antimicrobial activity of root and stem extracts of wild Eurycoma longifolia Jack (Tongkat Ali). J King Saud Univ Sci, 27, 23-30.

Klausmeyer P, McCloud T, Uranchimeg B, et al (2008). Separation and SAR study of HIF-1 $\alpha$ inhibitory tubulosines from Alangium cf. longiflorum. Planta Med, 74, 258-63.

Liu J, Mu J, Zheng C, et al (2016). Systems-pharmacology dissection of traditional Chinese medicine compound saffron formula reveals multi-scale treatment strategy for cardiovascular diseases. Sci Rep, 6, 19809.

Maestrini V, Cheang MH, Kotwinski P, et al (2017). Late anthracycline-related cardiotoxicity in low-risk breast cancer patients. J Am Coll Cardiol, 69, 2573-5.

Marino Gammazza A, Campanella C, Barone R, et al (2017). Doxorubicin anti-tumor mechanisms include Hsp60 post-translational modifications leading to the Hsp60/ p53 complex dissociation and instauration of replicative senescence. Cancer Lett, 385, 75-86.

Mitry MA, Edwards JG (2016). Doxorubicin induced heart failure: Phenotype and molecular mechanisms. IJC Hear Vasc, 10, 17-24.

Nan J, Wang Y, Yang J, Stark GR (2018). IRF9 and unphosphorylated STAT2 cooperate with NF- $\mathrm{kB}$ to drive IL6 expression. Proc Natl Acad Sci U S A, 115, 3906-11.

Neurohr GE, Terry RL, Lengefeld J, et al (2019). Excessive cell growth causes cytoplasm dilution and contributes to senescence. Cell, 176, 1083-97.e18.

Ouhtit A, Gaur RL, Abdraboh M, et al (2013). Simultaneous inhibition of cell-cycle, proliferation, survival, metastatic pathways and induction of apoptosis in breast cancer cells by a phytochemical super-cocktail: Genes that underpin its mode of action. $J$ Cancer, 4, 703-15.

Pang X, Fu W, Wang J, et al (2018). Identification of estrogen receptor $\alpha$ antagonists from natural products via in vitro and in silico approaches. Oxid Med Cell Longev, 2018, 1-11.

Sakurai N, Nakagawa-Goto K, Ito J, et al (2006). Cytotoxic Alangium alkaloids from Alangium longiflorum. Phytochemistry, 67, 894-7.

Scott JS, Bailey A, Davies RDM, et al (2016). Tetrahydroisoquinoline phenols: Selective estrogen receptor downregulator antagonists with oral bioavailability in rat. ACS Med Chem Lett, 7, 94-9.

Sonntag R, Gassler N, Bangen J-M, Trautwein C, Liedtke C (2014). Pro-apoptotic Sorafenib signaling in murine hepatocytes depends on malignancy and is associated with PUMA expression in vitro and in vivo. Cell Death Dis, 5, e1030.

Sosef MSM, Hong LT, Prawirohatmodjo S (1998). Plant Resources of South-East Asia No. 5(3). Timber Trees: Lesser-Known Timbers. Leiden: Backhuys Publishers.

Srdic-Rajic T, Santibañez JF, Kanjer K, et al (2017). Iscador Qu inhibits doxorubicin-induced senescence of MCF7 cells. Sci Rep, 7, 3763.

Takeuchi M, Saito Y, Goto M, et al (2018). Antiproliferative alkaloids from Alangium longiflorum, an endangered tropical plant species. J Nat Prod, 81, 1884-91.

Tiwary BK, Bihani S, Kumar A, Chakraborty R, Ghosh R (2015). The in vitro cytotoxic activity of ethno-pharmacological important plants of Darjeeling district of West Bengal against different human cancer cell lines. BMC Complement Altern Med, 15, 22.

Wiley CD, Schaum N, Alimirah F, et al (2018). Small-molecule MDM2 antagonists attenuate the senescence-associated secretory phenotype. Sci Rep, 8, 2410.

World Conservation Monitoring Centre (1998). Alangium
Alangium longiflorum Merr. Leaf Extract Induces Apoptosis

longiflorum. IUCN Red List Threat Species, 1998, e.T37769A10075897.

Xu G, Kuang G, Jiang W, Jiang R, Jiang D (2016). Polydatin promotes apoptosis through upregulation the ratio of $\mathrm{Bax} /$ $\mathrm{Bcl}-2$ and inhibits proliferation by attenuating the $\beta$-catenin signaling in human osteosarcoma cells. Am J Transl Res, 8, 922-31.

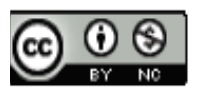

This work is licensed under a Creative Commons AttributionNon Commercial 4.0 International License. 